Reprod. Nutr. Dévelop., 1986, 26 (1 B), 379-380.

\title{
Influence centrale de quelques neuropeptides sur l'ingestion et l'apparition de la rumination chez le mouton
}

\author{
L. BUENO, Chantal HONDE, A. DURANTON
}

Station de Pharmacologie et Toxicologie,

I.N.R.A. 180 chemin de Tournefeuille, 31300 Toulouse.

Summary. The intracerebroventricular (ICV) administration of gastrin group peptides (tetragastrin, pentagastrin, gastrin 17), cholecystokinin octapeptide (CCK8) and corticotropin-releasing factor (CRF) resulted in a short-term reduction of food intake in hayfed ewe. Gastrin-related peptides promoted early rumination whereas CRF decreased the duration and CCK8 the rate of ingestion.

L'octapeptide terminal de la cholecystokinine (CCK8) est considéré comme l'un des facteurs de satiété à court terme chez le mouton (Della-Ferra et al., 1979 ; Bueno et al., 1983). Récemment nous avons montré que d'autres peptides (tétragastrine, gastrine 17) peuvent également affecter la prise de nourriture lorsqu'ils sont administrés par voie centrale (Honde et Bueno, 1984), mais par des mécanismes différents puisque l'action de la CCK8 est bloquée par la naloxone (Bueno et al., 1983) et celle de la gastrine par le proglumide (Bueno et al., 1984).

En conséquence ce travail avait pour objectif : 1) de préciser la nature de I'hypophagie induite par ces peptides (gastrine, CCK8) ; 2) d'évaluer chez le mouton I'influence du CRF intervenant dans la régulation du comportement alimentaire chez le rat (Gosnell et al., 1983).

Matériel et méthodes. L'expérience est réalisée au moyen de six brebis adultes de race Lacaune, pesant $50-60 \mathrm{~kg}$ et munies d'une canule en acier dont l'extrémité est située dans le ventricule cérébral latéral droit (Bueno et al., 1983). Les animaux placés en cage à métabolisme sont nourris entre $9 \mathrm{~h}$ et $17 \mathrm{~h}$ avec un foin de graminées de qualité moyenne donné à volonté. Les quantités ingérées sont déterminées par pesée des refus 0,$5 ; 2$ et $8 \mathrm{~h}$ après la distribution de foin. Un licol à capteur d'élongation permet l'enregistrement permanent des mouvements masticatoires.

Dans une $1^{\text {re }}$ série d'essais, tous les 2 jours, 5 min avant la distribution de l'aliment, les animaux ont reçu par voie intracérébroventriculaire (ICV) 0,5 ml d'eau stérile contenant ou non 26 pmoles $/ \mathrm{kg}$ de tétragastrine, pentagastrine, gastrine 17 (Interchim, France) CRF ovin (Sigma, USA) ou CCK8. Des administrations IV ont été réalisées selon le même protocole mais pour des doses 10 fois plus élevées. L'examen statistique des résultats a été réalisé par analyse de variance.

Résultats et discussion. La tétragastrine administrée par voie ICV, n'affecte pas la quantité de foin ingérée $30 \mathrm{~min}$; par contre, la quantité ingérée entre 30 et $120 \mathrm{~min}$ est réduite de $35,1 \%$ et la rumination débute beaucoup plus tôt $39 \pm 18 \mathrm{~min}$ après la distribution d'aliment (tabl. 1). A l'instar de la tétragastrine, 
la pentagastrine déclenche la rumination seulement $23 \pm 9$ min après le début de la prise de nourriture réduisant la quantité ingérée entre 30 et $120 \mathrm{~min}$. La gastrine 17 réduit immédiatement $(0-30 \mathrm{~min})$ l'ingestion qui par contre n'est pas affectée entre 30 et $120 \mathrm{~min}$.

TABL. 1. - Influence des neuropeptides sur les quantités ingérées, la vitesse d'ingestion et l'apparition de la rumination.

\begin{tabular}{|c|c|c|c|c|c|}
\hline & \multicolumn{3}{|c|}{ Quantité de foin ingérée $(\mathrm{g})$} & \multirow{2}{*}{$\begin{array}{c}\text { Vitesse }^{(a)} \\
d^{\prime} \text { ingestion } \\
(\mathrm{g} / \mathrm{min})\end{array}$} & \multirow{2}{*}{$\begin{array}{c}\text { Début } \mathrm{de}^{(\mathrm{b})} \\
\text { rumination }\end{array}$} \\
\hline & $0-0,5 \mathrm{~h}$ & $0,5-2 \mathrm{~h}$ & $0-8 \mathrm{~h}$ & & \\
\hline Témoin & $205 \pm 54$ & $316 \pm 73$ & $1287 \pm 248$ & $6,09 \pm 0,61$ & $112 \pm 44$ \\
\hline Tétragastrine & $192 \pm 35$ & $205 \pm 62^{*}$ & $1113 \pm 184$ & $6,31 \pm 0,29$ & $39 \pm 18^{* *}$ \\
\hline Pentagastrine & $213 \pm 55$ & $219 \pm 66^{* *}$ & $1349 \pm 290$ & $6,21 \pm 0,39$ & $23 \pm 9^{* *}$ \\
\hline Gastrine 17 & $116 \pm 34^{*}$ & $286 \pm 45$ & $1104 \pm 201$ & $5,75 \pm 0,41$ & $36 \pm 13^{* *}$ \\
\hline CCK8 & $66 \pm 26^{* *}$ & $127 \pm 38^{*}$ & $1198 \pm 262$ & $3,44 \pm 0,42^{*}$ & $87 \pm 36$ \\
\hline CRF & $75 \pm 33^{* *}$ & $172 \pm 50^{* *}$ & $1303 \pm 127$ & $5,87 \pm 0,49$ & $177 \pm 31^{*}$ \\
\hline
\end{tabular}

(a) Rapport quantité ingérée/durée d'ingestion observé pendant les 2 premières heures après la distribution. (b) Temps écoulé depuis la distribution du repas. Les valeurs sont les moyennes \pm l'écart-type * et ${ }^{* *}$ comparable aux valeurs témoins significativement différentes des valeurs témoins respectivement à $P<0,05$ et 0,01 .

L'action anorexigène de la CCK8 est plus rapide avec une réduction de $67,8 \%$ du niveau d'ingestion au cours de la $1^{\text {re }}$ demi-heure et de $43,5 \%$ de la vitesse d'ingestion, le délai d'apparition de la rumination étant comparable aux valeurs témoins.

Enfin le CRF ovin à même dose $(26$ pmoles $/ \mathrm{kg})$ réduit fortement les quantités ingérées sans affecter la vitesse $d$ 'ingestion; la rumination est tardive $(177 \pm 31$ vs $112 \pm 44 \mathrm{~min})$. En aucun cas ces peptides n'affectent la quantité ingérée pendant $8 \mathrm{~h}$; enfin des doses 10 fois plus élevées administrées par voie IV sont sans effet.

En définitive, ce travail montre que les peptides du groupe de la gastrine (tétra- et pentagastrine, gastrine 17) déclenchent une rumination précoce qui explique vraisemblablement leur effet inhibiteur sur l'ingestion. CCK8 et CRF apparaissent en revanche comme des hormones candidates a une régulation rapide de l'ingestion, la CCK8 réduisant la vitesse d'ingestion alors que le CRF déclenche l'arrêt de la prise de nourriture. A ce titre, le CRF pourrait être un signal important de satiété chez le mouton.

Bueno L., Duranton A., Ruckebusch Y., 1983. Antagonistic effects of naloxone on CCK-octapeptide induced satiety and rumino-reticular hypomotility in sheep. Life Sci., 32, 855-863.

Bueno L., Honde C., Fioramonti J., 1984. Proglumide : selective antagonism of the rumination but not gastric motor effects induced by pentagastrin in sheep. Life Sci., 34, 475-481.

Della-Ferra M. A., Baile C. A., 1979. Cholecystokinin-octapeptide continous picomole injections into the cerebral ventricles of sheep suppress feeding. Science, 206, 471-473.

Gosnell B. A., Morley J. E., Levine A. S., 1983. A comparison of the effects of corticotropin. Releasing factor and sauvagine on food intake. Pharmacol. Biochem. Behav., 19, 771-775.

Honde C., Bueno L., 1984. Evidence for central neuropeptidergic control of rumination in sheep. Peptides, 5, 81-84. 